\title{
CTLA-4 A49G polymorphism and autoimmune blood disease: A comment
}

\author{
CTLA-4 A49G polimorfizmi ve otoimmün kan hastalı̆̆l: Bir yorum
}

Viroj Wiwanitkit

Wiwanitkit House, Bangkhae, Bangkok, Thailand

\section{To the Editor,}

I read the recent publication on cytotoxic $\mathrm{T}$ lymphocyte antigen-4 (CTLA-4) A49G polymorphism with a great interest [1]. Aktürk et al. concluded that, "these data suggest that CTLA-4 A49G polymorphism does not contribute to the pathogenesis of lymphoproliferative diseases itself, nor does it increase the risk of autoimmune complications in patients with lymphoproliferative disease [1]." Aktürk et al. tried to determine allele frequencies and genotype distributions for some autoimmune blood diseases. There are some problems with their conclusion. First, the study included only a few patients and no controls. Second, not all autoimmune blood diseases were analyzed; therefore, they cannot conclude that their finding supports or refutes the contribution of the studied polymorphism to the pathogenesis or risk of disease. Third, when investigating a single polymorphism the possibility of other polymorphisms that were not investigated, must be considered.

\section{Conflict of interest statement}

The authors of this paper have no conflicts of interest, including specific financial interests, relationships, and/or affiliations relevant to the subject matter or materials included.

\section{References}

1. Aktürk F, Hançer VS, Küçükkaya R. Cytotoxic T lymphocyte antigen-4 (CTLA-4) A49G polymorphism and autoimmune blood diseases. Turk J Hematol. 2010;27:78-81. 